affect the prescription stability of adolescent patients who live with ADHD.

Methods We conducted a retrospective cohort study investigating 65 adolescents who were receiving prescriptions for ADHD medication. The patients were categorised into two groups, 'stable' and 'unstable', based on prescription changes over a three year period. The groups were then compared based on the medication prescribed, dose of medication, comorbidities, BMI and gender and reasons for prescription changes were noted.

Results The study found a statistically significant correlation between adolescents prescribed Elvanse and prescription changes (OR: $19.63 \mathrm{P} \leq 0.05$ ). Further to this Patients who were receiving an unlicensed dose of Concerta XL were also more likely to have a prescription change (OR: 11.00 $\mathrm{P} \leq 0.05)$. A key finding was the strong association between side effects and instability of prescriptions (OR: 936 $\mathrm{P} \leq 0.0001)$.

Conclusion This study revealed associations between patients prescribed Elvanse and increased changes to their medications. This also applied to those receiving an unlicensed dose of Concerta XL.

\begin{tabular}{ll} 
Abstract G622(P) Table 1 & Reasons for prescription change \\
\hline Reason for prescription change: & Total: \\
\hline Patients choice & 10 \\
Ineffective medication & 42 \\
Weight changes & 2 \\
Side effects & 18 \\
Co-existing conditions & 3 \\
Unrecorded & 9 \\
Total & 83 \\
\hline
\end{tabular}

This study also highlights the common reasons for medication change (table 1) in this transitionary period.

\section{G623 NON PSYCHIATRIC COMORBIDITIES IN ADHD: A SCOPING EXERCISE}

SJ Perera. Paediatric, Southend University Hospital, Westcliff-on-Sea, UK

10.1136/archdischild-2020-rcpch.537

\section{Aims}

- Literature review of comorbidities of Attention Deficit Hyperactivity Disorder (ADHD) with a view to identify publications on non-psychiatric comorbidities.

- Identify the non-psychiatric comorbidities in Paediatric Neurodevelopmental clinic patients with ADHD.

\section{Methods}

- A literature survey was conducted using MEDLINE under the terms ATTENTION DEFICIT HYPERACTIVITY DISORDER, ADHD, COMORBIDITY, CO-OCCURRENCE, MULTIMORBIDITY and DUAL DIAGNOSIS in metaanalysis OR Reviews articles published in English Language from 2013.

- Paediatric in-patient admissions for the age range 4-17 years during a consecutive period of 24 months was analysed to find out what the primary and secondary diagnoses were.
- Light House Child Development centre outpatient's clinic codes for ADHD and behavioural paediatrics were used to identify the cohort of children with a primary or a secondary diagnosis of ADHD to check for emerging comorbidities.

- A single clinician's sample was used for the preliminary survey

Results

- Sixty journal articles met the search criteria. Two articles on obesity, one on developmental motor coordination, five on atopic dermatitis, one on asthma and one on bedwetting met the non-psychiatric comorbidities (table 1).

- 1307 patients were admitted to the paediatric department between 01.01.2017-31.12.2018.one coded for Hyperkinetic disorder as a secondary diagnosis.one had ODD as a primary diagnosis.

- 3472 clinic episodes/patients were identified in neurodevelopment clinics with $\mathrm{ADHD} /$ behaviour problems.

- 40 patients were identified from the single clinician led clinic to have ADHD. And other comorbidities.

One had a dual diagnosis of ADHD and MCAD deficiency.

\begin{tabular}{lllll}
$\begin{array}{l}\text { Abstract G623 } \\
\text { yrs. Mable } 1\end{array}$ & Number of children 40. Age range 7-17 \\
\hline Dsorder & ADHD & $\begin{array}{l}\text { Psychiatric } \\
\text { comorbidity }\end{array}$ & $\begin{array}{l}\text { non Psychiatric } \\
\text { comorbidity }\end{array}$ & Mixed \\
\hline Primary DX & 37 & 3 & 4 & \\
Secondary Dx & 3 & 35 & & 17 \\
TOTAL & 40 & 38 & 4 & 17 \\
\hline
\end{tabular}

Obesity as a diagnosis was coded in none. Mixed group had Learning difficulties in 7 , sleep problems in 10 . The additional diagnoses of Looked after children adopted was recorded but not included as a non-psychiatric or mixed disorder.Management of comorbidities were studied.

Conclusions Non-psychiatric disorders are present in ADHD Children and young people (CYP) but in fewer numbers in this preliminary survey.

A detailed analysis of the outpatient data is ongoing and may shed more light into the prevalence of uncommon comorbidities of ADHD.

Limitations of the study and further recommendations will be discussed.

\section{G624 INCORPORATING COGNITIVE NEUROSCIENCE INTO INFLUENCING THE WIDER PICTURE OF CHILD HEALTH}

N Kamal. Community Paediatrics, George Still Forum, Kingston upon Hull, UK

\subsection{6/archdischild-2020-rcpch.538}

Various statistical data have been used as indices for the national profile of population and child health. Newer social factors have surfaced in the recent times such as aggression and criminalty amongst youth which compel us to include into the equation to reflect on Mental Health profile of the present youth and future community. Aim should be to offer due eminence to Child mental health. 